\title{
Role of Business Schools in SR Education and Perceptual Transformation Among \\ Prospective Employees
}

\begin{abstract}
The goal of this article is to study the impact of social responsibility education (SR education) on perceptive transformation among prospective employees regarding the understanding and attitude towards corporate social responsibility (CSR) under the assumptions of Actor Network Theory. The study was conducted at the micro level, using a survey research method, for the sample of 731 graduates from business and management schools, expected to contribute as responsible managers for the sake of sustainable development thus sustaining the life quality through business practices for future generations, especially in context of Pakistan as developing country. We found positive association between SR education and perceptive transformation among prospective employees through analysing the relationship via ordinary least squares regression analyses. The result shows, in recent years, Pakistani businesses and management schools have implemented SR education to successfully transform the ways in which Economic, Legal, Ethical and Philanthropic aspects of CSR are perceived. In doing so, they have also increased prospective employees' attraction towards socially responsible organisations and helped to develop job intention in budding entrepreneurs. Furthermore, this paper is the first of its kind to study the impact of SR education on prospective employees rather than customers and successfully contribute significant transformation on individual layers of CSR and then the attitudinal transformation as responsible managers.
\end{abstract}

Keywords: socially responsibility education; layers of CSR; perceptual transformation; organizational attractiveness; job intention 